\title{
A Study Determining the Factors Effective on Hygiene and Health Management in Stock Breeding Enterprises: The Case of Erzurum City
}

\author{
${ }^{1}$ Ayse Sezgin and ${ }^{2}$ Erdogan Sezgin \\ ${ }^{1}$ The Ministry of Agricultural and Rural Affairs, \\ Erzurum Agricultural Directorate of Province, 25100 Erzurum, Turkey \\ ${ }^{2}$ Eastern Anatolia Agricultural Research Institute, Dadaskent, 25090 Erzurum, Turkey
}

\begin{abstract}
A survey was conducted in 8 counties of Erzurum city with 165 farmers to determine the factors effective on hygiene and health management in stock breeding enterprises. The LIMPED software package was used to analyze the survey data using Logit Model. Four factors which are needed to consider for improving the hygiene and health conditions in stock breeding enterprises were used as dependent variables. These factors were as follows: routine health checks of the animals in the farm; cleansing hands and machine parts before milking; elaborating in the care and hygiene conditions of the animals in the farm and daily cleaning of the barn. It was concluded that age, education level and income of the farmer, regional differences, participation to agricultural extension training activities following agriculture-related broadcasts from mass media and the total number of culture race animals owned by the farm were effective on considering the hygiene and health management in stock breeding enterprises. In this context, it is necessary that the number of culture race animals should be increased; farmers should be trained on hygiene and health issues periodically and regularly with the help of mass media means and that farmers should be encouraged to make market based production so that their income could be increased.
\end{abstract}

Key words: Stock breeding, hygiene, health, Logit model, media, Erzurum

\section{INTRODUCTION}

The studies on the production of high quality, healthy and safe products have gained momentum. In this context, it is concluded that safe food products should be produced and managed primarily in enterprises having required hygiene conditions (DPT, 2006). For this reason, it is important that the hygiene problems in stock breeding enterprises should be dealt with care and the solutions ought to be discussed (Koyuncu et al., 2006).

The most significant problems of stock breeding sector in Turkey are the small number of animals per enterprise; conducting a traditional stock breeding activity; lack of health and hygiene; lack of technical equipment and low yield (Bakirci, 2009). The presence of hygiene maintenance problems in stock breeding in Turkey is often expressed.

Consideration of animal hygiene rules by owners and workers in stock breeding enterprises is the most important factor to be handled in the first step of the production. In this way, a strong base needed for healthy food production will be provided. Studies on raising awareness in enterprise owners for having a clean farm is of considerable importance. Having and maintaining a healthy and productive animal potential is seen as the most important condition to be competitive in this sector. However, as in most sectors in Turkey, health, quality, hygiene conditions and standards required in meat and diary products in stock breeding sector have not been met by current enterprises (Anonymous, 2004). It is thought that determining the social, economic and cultural factors effective on hygiene care in stock breeding by enterprise owners could have an importance for future studies to be conducted in this context.

\section{MATERIALS AND METHODS}

The 165 questionnaires applied to the farmers in Erzurum city makes up the primary material of the study. In addition, the literature review on the subject and the information obtained from public and private institutions and web sites make up the secondary material of the study.

Data collection: In the study, the judgment sampling method was used for the selection of counties where the survey would be applied. A total of 8 counties which could represent Erzurum city with respect to

Corresponding Author: Ayse Sezgin, The Ministry of Agricultural and Rural Affairs, 
socio-economic and geographical aspects were selected for the survey. They were Yspir and Oltu in the north of Erzurum city, Cat and Karayazi in the south, Askale county in the west, Pasinler in the east and Palandoken and Yakutiye in the middle. The number of enterprises in each county for conducting the questionnaires was determined taking the number of enterprises in each county into consideration and using proportional methods.

The sample size was determined considering the cattle assets belonging to 32065 enterprises registered to the Veterinary Data System of the Ministry of Agriculture and Rural Affairs. The General Administration of Protection and Control. The number of questionnaires applied to the farmers was determined using Simple Random Sampling method. The following equation was used to establish the number of questionnaires according to this method (Civek and Erkan, 1996).

$$
\begin{gathered}
\mathrm{n}=\frac{\mathrm{N} \sigma^{2}}{\mathrm{~N}-1 \mathrm{D}^{2}+\sigma^{2}} \\
\mathrm{D}=\left(\frac{\mathrm{d}}{\mathrm{t}}\right)^{2}
\end{gathered}
$$

Where:

$\begin{aligned} \mathrm{n}= & \text { Sample size } \\ \mathrm{N}= & \text { The unit number in the population (number) } \\ \mathrm{o}= & \text { Standard deviations } \\ \mathrm{d}= & \text { Acceptable error term }(\overline{\mathrm{x}} \times 0.10) \\ \mathrm{x}= & \text { Average cattle size (number) } \\ \mathrm{t}= & \text { t-distribution table value for a definite } \\ & \text { confidence interval }\end{aligned}$

In the study, these values were calculated as $\mathrm{N}=32065, \sigma=10.17, \mathrm{~d}=\overline{\mathrm{x}} \times 0.10, \overline{\mathrm{x}}=13.16$ cattle, $\mathrm{t}=1.65$.

$$
\mathrm{n}=\frac{32065(10.17)^{2}}{32064\left(\frac{1.3}{1.65}\right)^{2}+(10.17)^{2}}=165
$$

The number of questionnaires to be applied to farmers was estimated as 165 .

Data evaluation: The data collected during the survey study in Erzurum province was transferred to LIMPED software package. The Logit model and the Ordered Probit model were used to analyze the data. In econometrics studies, the categorical models whose dependent or explained variable is made up of responses like yes-no or successful-unsuccessful and coded as 0 and 1 are called as two-tailed methods with limited dependent variable. In cases where the dependent variable is qualitative, Limited
Dependent Variable Regression models are used. Two-tailed dependent variable defines whether the event happened or not. The dependent variable is assigned 1 when the event happens and 0 when the event does not happen (Yavuz, 2001; Gujarati, 1995). Three methods are used to estimate such kind of models. They are Linear Probability model, Logit model and Probit model. The Probit model is used as an alternative to the Logit model. As Logit and Probit Models give similar results, both can be used (Gujarati, 1995; Sarymepeli, 2000). However, the choice between the two generally results from ease of use and available software. Therefore, the Logit model is usually preferred over the Probit model (Gujarati, 1995; Sarymepeli, 2000).

The functional form of the regression model estimating the factors which are effective on this matter is as follows:

$$
\mathrm{Y}=\mathrm{f}\left(\mathrm{X}_{1}, \mathrm{X}_{2}, \mathrm{X}_{3}, \mathrm{X}_{4}, \mathrm{X}_{5}, \mathrm{X}_{6}, \mathrm{X}_{7}, \mathrm{X}_{8}, \mathrm{X}_{9}, \mathrm{X}_{10}, \mathrm{X}_{11}\right)
$$

where, $Y$ equals routine health checks of the animals in the farm. Yes $=1$ and $N_{0}=0$ (dummy) $X_{1}$ is the dummy variable (central counties $=1$; others $=0$ ), $X_{2}$ is age; $X_{3}$ is income; $\mathrm{X}_{5}$ is education; $\ldots \mathrm{X}_{8}$ is using mass media means for obtaining information.

\section{RESULTS AND DISCUSSION}

In the study, four factors that need to be considered for improving hygiene conditions in stock breeding farms were examined.

To explain the routine health checks of the animals in the farm, the logit model was applied and eight independent variables were used (Table 1). According to the results of the analysis, it was determined that the education level of the farmer and membership to the cooperative had a positive influence on the routine health checks of the animals in the farm and that it was statistically significant at $5 \%$ level. It was also found out

Table 1: The results of the logistic regression analysis for routine health checks of the animals in the farm

\begin{tabular}{lccl}
\hline Variables & Coefficients & $\mathrm{SE}$ & $\mathrm{p}$-value \\
\hline Constant & -3.0220 & 1.4745 & $0.0404^{* *}$ \\
Regional difference (Central & -0.5013 & 0.3664 & 0.1713 \\
counties:1; others:0) & & & \\
Age & -0.5924 & 0.4333 & 0.1716 \\
Income & 0.0001 & 0.0001 & 0.1220 \\
Training & 0.1354 & 0.0637 & $0.0334^{* *}$ \\
Membership to cooperative & 0.9699 & 0.4312 & $0.0245^{* *}$ \\
$\begin{array}{l}\text { Benefiting from } \\
\text { agricultural subsidies }\end{array}$ & 2.8777 & 0.7768 & $0.0002^{* * *}$ \\
Participation to agricultural & 1.1676 & 0.6491 & $0.0720^{*}$ \\
extension training & & & \\
Using mass media means & 0.1290 & 0.1598 & 0.4197 \\
\hline
\end{tabular}

Log likelihood: $89.1581 \mathrm{McFadden} \mathrm{R}^{2}$ : $0.2093 \chi^{2}(8)$ : $47.2058^{* * *}$; Original estimations $^{* * *}: \mathrm{p}<0.01^{* *}: \mathrm{p}<0.05^{*}: \mathrm{p}<0.1 ; \mathrm{SE}=$ Standard Error 
Table 2: The results of logistic regresyon analysis for cleansing hands and

\begin{tabular}{lccl}
\multicolumn{4}{c}{ machine parts before milking } \\
\hline Variables & Coefficients & SE & p-value \\
\hline Constant & 0.0113 & 1.0791 & 0.9916 \\
$\begin{array}{l}\text { Regional difference (Central } \\
\text { counties:1; others:0) }\end{array}$ & 0.2450 & 0.0612 & $0.0001^{* * *}$ \\
Age & -0.3828 & 0.1404 & $0.0064^{* * *}$ \\
Income & 0.1520 & 0.2055 & 0.4596 \\
$\begin{array}{l}\text { Training } \\
\text { Membership to cooperative }\end{array}$ & 0.4173 & 0.1936 & $0.0311^{* *}$ \\
$\begin{array}{l}\text { Benefiting from mass } \\
\text { media means }\end{array}$ & 0.0985 & 0.5234 & 0.8507 \\
$\begin{array}{l}\text { Participation to agricultural } \\
\text { extension activities }\end{array}$ & 1.2329 & 0.1981 & 0.1013 \\
\hline
\end{tabular}

Log likelihood: -56.9605 McFadden $\mathrm{R}^{2}$ : $0.2813 \chi^{2}$ (7): $44.5710^{* * *}$; Original calculations: $\mathrm{p}<0.01^{* *} \mathrm{p}<0.05^{*} \mathrm{p}<0.1 ; \mathrm{SE}=$ Standard Error

that benefiting from agricultural subsidies applied by the government affected the dependent variable positively and that it had a statistical significance at $1 \%$ level. The participation to agricultural extension training activities was found to affect the variable dependent on animals and it was determined to have a statistical significance at $10 \%$ level. It can be stated that the farmer training activities by several institutions on the necessity of routine health checks had an influence on the results obtained.

The Logit method and seven independent variables were used to determine the factors which were effective on cleansing hands and machine parts before milking (Table 2). According to the results of the analysis, the coefficients of all parameters were found to be significant. It was determined that the regional differences used as dummy variable affected the dependent variable positively and that it was statistically significant at $1 \%$ level.

The farmers in the central county were more inclined to pay attention to hygiene during milking. It was determined that the age factor affected the dependent variable negatively and that it was statistically significant at $1 \%$ level.

It was revealed that consideration to hygiene conditions of milking decreased as the farmer age increased. It was also determined that the education level of the farmer affected the dependent variable positively and that it had a $5 \%$ statistical significance. It was observed that as the education level of farmer increased, consideration to hygiene conditions of milking naturally increased. Participation to agricultural training activities was also found to have a positive influence on the dependent variable and it was statistically significant at $1 \%$ level.

It is important to elaborate in the care and hygiene of the animals in the farm. This case was taken as dependent variable and eight independent variables were used in the
Table 3: The results of the logistic regression analysis for elaborating in the care and hy giene conditions of animals in the farm

\begin{tabular}{lccc}
\hline Variables & Coefficients & $\mathrm{SE}$ & $\mathrm{p}$-value \\
\hline Constant & -1.4206 & 2.1491 & 0.5086 \\
$\begin{array}{l}\text { Regional difference } \\
\text { (Central:1; others:0) }\end{array}$ & -0.0198 & 0.0888 & 0.8233 \\
Age & -0.0191 & 0.2238 & 0.9320 \\
Income & 0.0100 & 0.4168 & 0.9808 \\
Training & 0.1790 & 0.5383 & 0.7394 \\
$\begin{array}{l}\text { Total number of domestic } \\
\text { animals in the farm }\end{array}$ & -1.1587 & 0.7486 & 0.1216 \\
$\begin{array}{l}\text { Total number of culture } \\
\text { race animals in the farm }\end{array}$ & 1.5367 & 0.6849 & $0.0248^{* *}$ \\
$\begin{array}{l}\text { Benefiting from mass media means } \\
\text { Participation to agricultural } \\
\text { extension training activities }\end{array}$ & 1.0575 & 0.3883 & $0.0065^{* * *}$ \\
\hline
\end{tabular}

Log likelihood: -50.9862 McFadden R Square: $0.1893 \chi^{2}$ (8): $23.8134^{* * *}$ Original calculations ${ }^{* * *} \mathrm{p}<0.01^{* *} \mathrm{p}<0.05^{*} \mathrm{p}<0.1 ; \mathrm{SE}=$ Standard Error

Table 4: The results of logistic regression analysis for daily cleaning of the bam in the farm

\begin{tabular}{|c|c|c|c|}
\hline Variables & Coefficients & SE & $\mathrm{p}$-value \\
\hline Constant & 6.7497 & 3.4693 & $0.0517^{*}$ \\
\hline $\begin{array}{l}\text { Regional difference (central } \\
\text { counties: } 1 \text {; others: } 0 \text { ) }\end{array}$ & -0.0086 & 0.1284 & 0.9469 \\
\hline Age & -1.2972 & 0.4576 & $0.0046^{* * *}$ \\
\hline Income & 0.0002 & 0.0002 & 0.3312 \\
\hline Training & 0.3483 & 1.1988 & 0.7714 \\
\hline $\begin{array}{l}\text { Total number of domestic } \\
\text { animals in the farm }\end{array}$ & -1.5107 & 1.2304 & 0.2195 \\
\hline $\begin{array}{l}\text { Total number of culture } \\
\text { race animals in the farm }\end{array}$ & 0.0238 & 0.5804 & 0.9673 \\
\hline Benefiting from agricultural subsidies & 0.2069 & 1.2166 & 0.8650 \\
\hline Benefiting from mass media means & 1.3423 & 0.5418 & $0.0132^{* *}$ \\
\hline $\begin{array}{l}\text { Participation to agricultural } \\
\text { extension training activities }\end{array}$ & 1.1721 & 0.8597 & 0.1727 \\
\hline
\end{tabular}

Logit model for the case. The results are shown in Table 3. The coefficients of all parameters were found to be significant. It was determined that the number of culture race animals affected the dependent variable positively and it was statistically significant at $5 \%$ level. Following agriculture-related broadcasts from mass media means was also found to have a positive influence on the dependent variable and it was statistically significant at $1 \%$ level. It was found out that participation to agricultural extension training activities also affected the dependent variable positively and that it was statistically significant at $10 \%$ level.

The Logit model was applied to determine the factors having an influence on daily routine cleaning of the barn in the farm. In addition, nine independent variables were used (Table 4). According to the analysis results, the coefficients of all parametres were significant. It was determined that routine cleaning of barn decreased as the farmer age increased and that this independent variable was found to be statistically significant at $1 \%$ significance level. It can be stated that as daily barn cleaning is a tiring and strenuous job, older farmers do it less frequently. 
Benefiting from mass media means for agricultural extension training programs also affected the dependent variable positively and it was found to be statistically significant at $5 \%$.

It is known that healthy animal products can be obtained from healthy animals. Therefore, the reliability of animal products depends on the extent of consideration given to hygiene conditions in stock breeding enterprises (Blaha, 2010). Complying with hygiene rules has an important role in animal welfare and preventing animal diseases in animal husbandry (Ondrasovic, 2009). Within hygiene rules context, there are several issues such as environmental conditions under which animals are raised, protection against diseases, applying appropriate treatment for diseases and giving enough consideration to hygiene rules at every stage of the production. Within environmental conditions context, regular removal of barnyard manure and routine cleaning of the barn is a factor increasing animal health and welfare to a great extent (Novak et al., 2005). It is thought that determining the factors having an influence on the extent of consideration given to hygiene conditions in animal husbandry enterprises where animal products that has an important place in human nourishment is produced will help develop policies regarding animal husbandry. Therefore, this study determined the factors affecting the extent of consideration given to hygiene conditions in animal husbandry enterprises.

In the context of the study, a survey was applied to a total of 165 farmers in eight counties of Erzurum city. The data of the survey was analyzed in LIMPED software package using the Logit model, a limited dependent variable model. Four factors that should be considered for improving the hygiene conditions in stock breeding enterprises were examined in the research area.

\section{CONCLUSION}

In this study, it was determined that age, education level and income of the farmer, regional differences, participation to agricultural extension training activities, following agriculture-related broadcasts from mass media and the total number of culture race animals owned by the farm were effective on considering the hygiene and health management in stock breeding enterprises.

\section{RECOMMENDATIONS}

In the light of the results obtained, the following suggestions can be put forward to raise the awareness of the farm owners for caring and paying attention to hygiene issues in stock breeding.

According to the results of this study, it was found out that hygiene conditions were considered more as the number of culture race animals of the farm increased.
Therefore, the number of culture race animals should be increased in the stock breeding enterprises. In this context, training activities and technical support is needed to promote artificial insemination.

Agricultural extension activities have an important role in promoting the agricultural productivity and improving agricultural sector (Bernet et al., 2001; Wadsworth, 2003). In line with the result of this study, training meetings should regularly be held in certain periods to emphasize the importance and necessity of complying with hygiene rules in stock breeding enterprises.

It was found out in studies conducted earlier in parallel to the results of the study that there was a strong correlation between adoption of innovations and following the mass media means and that mass media means had an influence on adopting the innovations (Cicek et al., 2008). In this context, it is necessary that training programs should be organized using local mass media means to emphasize the hygiene rules in stock breeding enterprises.

In the light of the results obtained from the study, selling the products produced in these enterprises at real prices is of great importance for increasing the incomes. Since, market based production is to put the producers in a competitive environment, it is necessary to do a higher quality production complying with certain criteria. The first requirement of this is to give enough consideration to hygiene conditions at every stage of the production process from the beginning to the end.

For this reason, it is necessary to make arrangements to provide and facilitate marketing possibilities for the farmers. In this context, making and supporting arrangements for the establishment of local manufacturing industries can be recommended.

\section{REFERENCES}

Anonymous, 2004. The report of production and marketing policies commission. T.R. The Ministry of Agriculture and Rural Affairs, Agriculture Congress II, Ankara.

Bakirci, M., 2009. The rural development compound of support fund of European Union Pre-Membership. The State of Turkey and possible impacts. East. Geogr. J., 2009: 53-78.

Bernet, T., O. Ortiz, R.D. Estrada, R. Quiroz and S.M. Swinton, 2001. Tailoring agricultural extension to different production contexts: a user-friendly farmhousehold model to improve decision-making for participatory research. Agric. Syst., 69: 183-198.

Blaha, T., 2010. Animal hygiene the basis of pre-harvest food safety for wholesome food of animal origin. http://www.isah-soc.org/documents/mainspeakers/ 3\%20BlahaGermany.doc. 
Cicek, H., Y. Cevger and M. Tandogan, 2008. Socioeconomic factors affecting the level of adoption of innovations in dairy cattle enterprises. Ankara Univ. J. Vet. Fac., 55: 183-187.

Civek, A. and O. Erkan, 1996. Research and Sampling Methods in Agricultural Economy. Gaziosmanpasa University, Agricultural Faculty Publications No. 12, Tokat.

DPT., 2006. Food safety, special commission of plant and animal health. The Undersecretariat of State Planning Organization. The 9thDevelopment Plan. (2007-2013), Ankara.

Gujarati, D.N., 1995. Basic Econometrics. 3rd Edn., McGraw-Hill, Inc., New York, pp: 540-583.

Koyuncu, E., A. Pala, T. Savap, A. Konyaly and C. Atapoolu et al., 2006. An investigation on determining the technical problems in goat raising enterprises. Members of Sheep and Goat Breeding Union in Canakkale.
Novak, P., J. Vokralova, I. Knizkova and P. Kunc, 2005. Animal hygiene, welfare and environmental protection in relation to implementation of $\mathrm{EU}$ legislation in animal production. Folia Vet., 49: S12-S16.

Ondrasovic, M., 2009. Hygiene of animal rearing and its importance in prevention of diseases and satisfying welfare requirements. Folia Vet., 53: 117-119.

Sarymepeli, M., 2000. Econometrics Handbook. 1st Edn., Gazi Book Store, Ankara.

Wadsworth, J., 2003. Developing Efficient Extension Strategies: Results of an Experiment Involving Costa Rican Livestock Producers. Department of Agriculture and Horticulture, University of Reading, Reading.

Yavuz, F., 2001. Theory and Application in Econometrics. The Faculty of Agricultural Engineering, Publication No. 185, Ataturk University, Erzurum. 